\title{
Potensi Pengembangan Agregator Berita dengan Konsep Slow Technology Berbasis Human Centered
}

\author{
Ilham Fariq Maulana, Irwansyah \\ Fakultas Ilmu Sosial dan Ilmu Politik, Universitas Indonesia \\ ilham.fariq@ui.ac.id
}

\begin{abstract}
Digital journalism in Indonesia is placing the speed of news presentation and distribution as a significant factor for the audience or news readers. The presence of news aggregators such as LINE Today are considered to be able to present news with actual issues and curated topics and also filter news to attain quality content. However, based on previous research, there are still several issues regarding news aggregators such as being repetitive, biased, and producing irrelevant news. This research aims to offer development ideas through the concept of slow technology by placing humans amid technology to fill academic debates regarding the shortcomings of news presentation from news aggregators. This study uses a constructivism paradigm with a case study research strategy and a single-case design. Research analysis uses a pattern-matching model to involve a comparison of predicted patterns and effects with those that have been observed empirically and identified. The results show that there is a potential for developing news aggregators based on the integration of roles among stakeholders, by introducing awareness of balance between the increasing speed of information and communication technology and the more limited speed of personal information processing. This research fills gaps on issues and problems that news aggregators often encounter to provide constructive solutions through the potential of ICT design that reflects human values, such as trust, integrity, and honesty.
\end{abstract}

Keywords: news aggregator; digital journalism; slow technology; human centered design; line today

\begin{abstract}
Abstrak
Jurnalisme digital di Indonesia saat ini menempatkan kecepatan penyajian dan distribusi berita menjadi faktor utama bagi para audiens atau khalayak berita. Keberadaan dari agregator berita seperti LINE Today dianggap bisa menyajikan berita dengan isu aktual dan berbagai topik yang telah terkurasi serta menyaring berita agar lebih berkualitas. Namun, berdasarkan penelitian yang telah dilakukan, tetap ditemui sejumlah isu mengenai agregator berita seperti berita yang repetitif, bias, dan tidak relevan. Tujuan dari penelitian ini adalah mampu menawarkan ide pengembangan melalui konsep slow technology dengan menempatkan manusia di tengah teknologi untuk mengisi debat akademis mengenai kekurangan dari sajian berita agregator berita. Penelitian ini menggunakan paradigma konstruktivisme dengan strategi penelitian studi kasus dengan desain single case, kemudian analisis menggunakan model pattern-matching untuk melibatkan perbandingan pola yang diprediksi dan atau efek dengan yang telah diamati secara empiris, dan identifikasi. Hasil penelitian menunjukkan terdapat sejumlah potensi untuk mengembangkan agregator berita didasarkan dari integrasi peran antar stakeholder dengan memperkenalkan kesadaran keseimbangan antara meningkatnya kecepatan teknologi informasi dan komunikasi dengan kecepatan pemrosesan informasi manusia yang lebih terbatas. Penelitian ini mengisi gap mengenai isu dan masalah yang kerap ditemui dari news aggregator sehingga mampu memberikan solusi konstruktif melalui potensi desain ICT yang mencerminkan nilai-nilai manusia, seperti kepercayaan, integritas, dan kejujuran.
\end{abstract}

Kata Kunci: agregator berita; jurnalisme digital; slow technology; human centered design; line today

Korespondensi: Dr. Irwansyah, M.A., Departemen Ilmu Komunikasi Universitas Indonesia, Jl. Salemba Raya No. 4, Senen, Jakarta Pusat 10430, 081511911183, Email: dr.irwansyah.ma@gmail.com Menyerahkan: Juni 2020, Diterima: Juli 2020, Terbit: Juli 2020

ISSN: 2549-0559 (cetak), ISSN: 2549-1946 (online), Website: http://jurnal.unpad.ac.id/kajian-jurnalisme 
Volume 04 Nomor 01 Tahun 2020

DOI: $10.24198 / j k j . v 4 i 1.27606$

\section{PENDAHULUAN}

Saat ini jurnalisme digital di Indonesia memasuki tahap dimana kecepatan penyajian dan distribusi berita menjadi faktor utama bagi para audiens atau khalayak berita. Maka, kini lebih banyak orang menganggap bahwa internet seharusnya menjadi media yang 'cepat' daripada yang 'lebih detail' dalam penyajian informasi (Widodo, 2017). Berawal dari pemaparan bahwa saat ini, berita media daring di Indonesia cenderung tidak lagi mengedukasi masyarakat dan hanya lebih mementingkan kepentingan iklan dengan eksposur berita yang remeh temeh (Dewan Pers, 2018). Maka, keberadaan dari agregator berita seperti LINE Today dianggap bisa menyajikan berita dengan isu aktual dan berbagai topik yang telah terkurasi serta menyaring berita agar lebih berkualitas dari sisi isi artikel (Prihastomo, 2019).

Secara umum, proses dari agregasi berita menggunakan kolaborasi algoritma dengan editor yang mengumpulkan informasi berbeda bersumber di berbagai situs berita dan mengaturnya kembali untuk dipresentasikan kembali di satu situs (Chyi, Lewis, \& Zheng, 2016). Kemudian dalam Choi \& Kim (2017), proses selanjutnya agregator berita akan memilih artikel berita dari pelbagai perusahaan berita (baik manusia atau mesin), selanjutnya merangkai artikel-artikel tersebut dengan rangkaian urutan yang dibuat oleh agregator berita terkait, dan akhirnya menyajikan artikel-artikel tersebut dalam bentuk seperti daftar headlines (tampilannya cenderung sedikit kalimat pembuka, nama penerbit, dan waktu terbit). LINE Today mengaplikasikan langkah-langkah tersebut dalam proses bagaimana mengategorikan, mengumpulkan, serta menampilkan konten berita dari pelbagai situs media daring (Parahita, 2019).

Namun, berdasarkan sejumlah kasus pada penelitian terdahulu terdapat isu seringnya berita yang repetitif atau muncul beberapa kali, mudah ditemukan dalam agregator berita. Meskipun hal itu cenderung lebih disebabkan dari sumber dari mana penerbit beritanya atau perusahaan-perusahaan media daring (Choi \& Kim, 2017). Pada kasus ini, kualitas jurnalisme digital bisa terdampak tidak hanya bagi perusahaan media tetapi juga agregator berita. Berdasarkan dari hasil analisis data yang telah ada dilakukan Choi \& Kim (2017) pada 1.000 orang berusia 20 tahun ke atas di Korea Selatan, menunjukkan hubungan antara penyajian berita yang berulang dengan persepsi tentang berita yang berulang memiliki hubungan positif dengan analisis korelasi Pearson $(r=0,157, \mathrm{p}<0,001)$. Artinya, semakin sering seseorang terpapar dengan berita yang berulang, semakin besar kemungkinan seseorang menganggapnya sebagai masalah serius. Apabila diaplikasikan pada konteks Indonesia, hal tersebut dapat dihubungkan dengan pengaduan kasus pada Dewan Pers (2018), mengenai pelanggaran kode etik yang terjadi di rentang waktu Januari hingga April diketahui 60 pengaduan masuk dengan separuhnya dilakukan oleh media siber. Data ini mewakili bagaimana urgensitas penyajian berita dan praktik dari media digital serta agregator berita merupakan isu yang perlu dikaji kembali.

Karena saat ini keberadaan agregator berita menjadi garda depan dalam preferensi khalayak artikel berita daring sebagai sumber untuk mendapatkan berita (Hargittai et al.; Sundar dalam Choi \& Kim, 2017). Hal itu ditunjukkan dari hasil survey mobile yang dilakukan oleh JakPat pada tahun 2017, mengenai sumber berita populer di Indonesia. Berdasarkan data yang diperoleh menunjukkan LINE Today menempati posisi kedua setelah Facebook (Cahyo, 2017). Ini menjelaskan kemampuan LINE Today yang sukses mendapatkan simpati dari penggunanya meski baru setahun berjalan. Keberhasilan ini disebut karena agregator berita bisa berperan sebagai penyaring dari berita bohong sehingga mampu memoderasi dan asal sumber terpercaya berita. Pemanfaatan teknologi Artificial Intelligence (AI) pada platform agregator berita juga dinilai bisa merekomendasikan berita berdasarkan minat pembacanya sehingga penyaringan 
berita seperti terjamin kualitasnya (Prihastomo, 2019).

Lebih jauh, munculnya praktik repetisi berita yang dilakukan sejumlah perusahaan media daring disebut juga sebagai perilaku kloning berita. Bagi para pelaku media istilah ini justru cukup sering dipraktikkan, terutama di kalangan jurnalis, tidak sedikit juga masyarakat umum mengetahui adanya praktik tersebut. Namun, dari kalangan jurnalis sendiri tidak pernah menyepakati praktik dan istilah tersebut ke dalam profesinya (Hidayat \& Anisti, 2015).

Kata kloning sendiri dapat dimaknai sebagai mengambil, meniru, dan menyamakan isi berita dengan media lain. Sehingga bisa digarisbawahi jika tindakan pengkloningan berita dapat dikategorikan suatu tindakan yang melanggar kode etik jurnalistik. Apalagi jika dalam proses peliputannya tidak menyertakan sumber atau asal dari berita itu sendiri. Namun, saat ini praktik pengkloningan berita seakan mulai bergeser determinismennya. Bahkan praktik ini sudah mulai menggunakan istilah lain. Sekarang praktik ini di kalangan jurnalis mengistilahkannya sebagai aktivitas rewrite atau menulis ulang kembali berita dengan menyertakan sumber berita dalam tulisannya (Hidayat \& Anisti, 2015).

Selain itu dalam perspektif isu lain mengenai penyajian artikel berita yang diterbitkan bisa menyebabkan bias dan kadang bermasalah. Hal itu diklaim disebabkan distribusi berita oleh agregator berita (dalam hal ini adalah Google News) yang cenderung terlalu sering menyajikan berita dari platform media tertentu dan kurang menyajikan dari platform media lain. Kemudian algoritma juga dinilai kesulitan dalam mengidentifikasikan cerita utama topik yang didasarkan oleh gambar dibandingkan teks sehingga hal itu mengurangi bobot dari laporan dari bergambar (Haim, Graefe, \& Brosius, 2018). Perlu diketahui salah satu kriteria dan aspek pertama untuk mendefinisikan aturan pemilihan berita adalah nilai berita (news values) (Wendelin, Engelmann, \& Neubarth, 2017). Nilai berita merupakan kriteria yang relevan baik bagi jurnalis dan audiensnya (Eilders; Lee; Shoemaker \& Reese dalam Wendelin et al., 2017). Maka agregator berita akan mendasarkan kurasi dan penyajian berita dari nilai berita.

Dari penjabaran sebelumnya menunjukkan bagaimana kinerja dari agregator berita sangat berkorelasi kuat dengan pembaca dan pengguna berita dalam mendistribusikan beritanya. Sehingga fungsi dari agregator berita meski telah menggunakan editor untuk mengkurasi, juga menggunakan teknologi AI dan machine learning sehingga kualitas berita dapat sesuai dengan kriteria agregator, tetapi masih memiliki keterbatasan terhadap distribusi atau penyajian berita. Hal tersebut dinilai karena agregator berita cenderung mengumpulkan berbagai macam informasi serta konten berita dengan dasar media yang sering dikunjungi atau dibaca sehingga hal itu menjadi rujukan bagi pembaca (Parahita, 2019). Maka apabila perusahaan-perusahaan media rujukan pembaca ini membuat berita dengan tipikal yang sama akan membentuk pola repetitif penyajian artikel berita. Meski artikel-artikel dari perusahaan-perusahaan berita itu sudah melewati proses agregasi dan menyesuaikan kriteria kualitas berita yang akan disajikan oleh agregator berita.

Berangkat dari hal tersebut, memang terlihat adanya pergeseran konteks sosial dari jurnalisme secara fundamental (Hermans \& Drok, 2018). Hal tersebut dinilai karena teknologi informasi digital mengalami proses informatization atau informatisasi, yakni masuk pada segala aspek publik dan kehidupan pribadi (Castells, 2011); Webster, 2006). Dapat dikatakan informatisasi memfasilitasi hadirnya infrastruktur informasi publik dan komunikasi yang baru dengan konektivitas dan interaktivitas sebagai kata kuncinya (van der Haak, Parks, \& Castells, 2012).

Sehingga ide dan pemikiran untuk menempatkan manusia di tengah teknologi menjadi sebuah rujukan baru dalam mengatasi dampak-dampak dari cepatnya teknologi yang tidak diiringi dengan peran para pengguna teknologi informasi dan komunikasi (ICT) di dalamnya. 
Volume 04 Nomor 01 Tahun 2020

DOI: $10.24198 /$ jkj.v4i1.27606

Konsep tersebut disebut sebagai slow tech yang diperkenalkan di dalam komunitas etika dalam ETHICOMP 2013 (Patrignani \& Whitehouse, 2015). Slow Tech menyarankan pandangan jangka panjang tentang ICT dengan menempatkan manusia sebagai pusatnya. Secara ideal, mirip dengan cara di masa Renaisans Italia - dengan fokus pada pentingnya manusia. Slow Tech dapat menawarkan cara baru dalam memandang ICT di abad ke-21 (Patrignani \& Whitehouse, 2015). Maka dengan demikian, Slow Tech bertujuan untuk menyediakan perancang praktis ICT generasi mendatang berupa arahan praktis yang dapat membantu mereka membuat berbagai pilihan etis yang harus didorong dalam pengembangan sistem komputer (Patrignani \& Whitehouse, 2015). Ini mendorong desainer masa depan dan berbagai pemangku kepentingan (stakeholder) yang terlibat dalam penggunaan ICT tersebut untuk ikut berpikir ke depan dalam jangka panjang teknologi komputer (Patrignani \& Whitehouse, 2015).

Adapun Slow Tech, sebagai sebuah istilah, telah muncul dari beberapa bidang disiplin ilmu yang berbeda yang ditandai oleh berbagai pengaruh. Pada awal abad 21, beberapa peneliti menilai Slow Tech sebagai bentuk ICT yang dikarakteristikkan dalam perhatian pada refleksi diri, mindfulness dan mental rest (Hallnäs \& Redström, 2001). Slow Tech juga telah digunakan untuk menggambarkan dampak budaya dan sosial dari perangkat mobile ICT (Kopomaa, 2007), dan investigasi masalah yang muncul karena kurangnya tangguhnya keahlian teknis dan lemahnya ketahanan publik dari masuknya pelbagai teknologi modern (Patrignani \& Whitehouse, 2015).

Maka berbicara dalam konsep-konsep yang terdapat dalam ICT ini meliputi halnya Good and Fair ICT. Hal ini berkesesuaian dengan ide human experience platforms yang digunakan untuk agregator berita. Pada konsep Good ICT merujuk pada ICT yang dikembangkan dengan menempatkan manusia sebagai pusat perhatian teknologi itu sendiri (Patrignani \& Whitehouse, 2015). Good ICT memperkenalkan kesadaran eksplisit keseimbangan antara meningkatnya kecepatan ICT dan kecepatan pemrosesan informasi manusia yang lebih terbatas. Dengan demikian, Good ICT harus dirancang dengan mempertimbangkan batasan manusia. Untuk menguasai bentuk-bentuk desain ICT baru ini akan membutuhkan desainer dan pihak-pihak yang lebih besar untuk meningkatkan kompetensi khusus dari teknologi itu (Patrignani \& Whitehouse, 2015). Konsep ini berkaitan erat dengan ide human centered-design yang memulai dari premis bahwa keyakinan, nilai, perasaan, dan ambisi individu adalah penting karena mereka membentuk fondasi untuk siapa individu-individu itu dan apa yang mereka inginkan dari organisasi tempat mereka terlibat (Deloitte, 2020).

Konsep kedua dari slow tech yakni fair ICT, didasarkan pada penggunaan ICT yang wajar. Ini memiliki kesamaan tertentu dengan inisiatif penggunaan yang adil di bidang konsumsi makanan atau perdagangan secara luasnya. Ketenagakerjaan yang adil juga merupakan elemen penting dari fair ICT, khususnya produksi ICT yang terjadi di bawah kondisi yang manusiawi (Patrignani \& Whitehouse, 2015). Sehingga ide ini melihat adanya kemungkinan untuk menghapus bias dan menekankan nilai dan etika. Agar pengalaman beresonansi, ICT haruslah mencerminkan nilai-nilai manusia, seperti kepercayaan, integritas, dan kejujuran semua faktor emosional yang dirasakan manusia (Deloitte, 2020). Hal ini dipandang begitu banyak aspek teknologi kognitif dan afektif dalam perjalanan pengalaman manusia yang harus dimasukkan dengan pelbagai pertimbangan etis - dan juga nilai-nilai organisasi mereka ke dalam pengembangan solusi AI ICT milik mereka sendiri (Deloitte, 2020).

Maka dari konsep dan pemaparan dari isu sebelumnya, tujuan dari penelitian ini adalah mampu mengisi debat akademis mengenai kekurangan dari sajian berita agregator berita dengan menawarkan ide pengembangan melalui konsep slow technology yang menempatkan manusia di tengah teknologi. Sehingga penelitian ini memiliki rumusan masalah sebagai berikut: (1) 
Bagaimana stakeholder LINE Today melihat perkembangan jurnalisme digital di Indonesia? (2) Bagaimana stakeholder melihat agregator berita LINE Today sebagai platform distribusi dan penyajian berita? (3) Bagaimana potensi perkembangan dari teknologi agregator berita dalam meminimalisasi bias, repetisi, dan inkorelasi berita melalui peran dari stakeholder?

\section{METODE}

Paradigma yang digunakan dalam penelitian ini adalah konstruktivisme atau konstruktivisme sosial (sering dianggap mirip dengan interpretivisme). Konstruktivis sering membahas proses interaksi antara individu dan fokus pada konteks spesifik di mana orang hidup dan bekerja untuk memahami pengaturan sejarah dan budaya. Konstruktivis sosial percaya bahwa individu mencari pemahaman tentang dunia tempat mereka hidup dan bekerja. Peneliti konstruktivis menyadari bahwa latar belakang mereka sendiri membentuk interpretasi mereka, dan mereka memposisikan diri dalam penelitian untuk mengakui bagaimana interpretasi mereka mengalir dari pengalaman pribadi, budaya, dan sejarah mereka. Maka ini bisa menjelaskan individu mengembangkan makna subjektif dari pengalaman mereka dengan makna yang diarahkan pada objek atau benda tertentu (Creswell, 2014).

Penelitian ini menggunakan strategi dari metode studi kasus dengan desain penelitian single case. Metode penelitian studi kasus (case study) merupakan bentuk penelitian yang dapat menjawab sejumlah isu pada suatu fenomena dalam cabang ilmu sosial. Yin (mendefinisikan studi kasus sebagai suatu metode dalam melakukan suatu penelitian terhadap fenomena yang terjadi melalui fokus pada pengalaman hidup seseorang (real life context), ketika terdapat gap antara fenomena dengan konteks yang ada, atau ketika menggunakan multiple source evidences (Borbasi, 2004).

Selain itu, studi kasus bisa menambahkan penekanan pada analisis kasus meski menggunakan sedikit jumlah kejadian dalam suatu desain penelitian. Maka bila dilihat dari tujuannya, studi kasus merupakan salah satu metode penelitian kualitatif yang berbasis pada pemahaman dan perilaku manusia berdasarkan perbedaan nilai, kepercayaan, dan teori saintifik (Polit \& Beck, 2004 ; Borbasi 2004). Menurut Yin (2009) desain studi kasus harus dipertimbangkan ketika: (a) Fokus penelitian ini adalah untuk menjawab pertanyaan "bagaimana" dan "mengapa"; (b) Peneliti tidak dapat memanipulasi perilaku orang-orang yang terlibat dalam penelitian ini; (c) Peneliti ingin membahas kondisi kontekstual karena yakin kondisi tersebut relevan dengan fenomena yang diteliti; atau (d) Batas tidak jelas antara fenomena dan konteks.

Peneliti harus mempertimbangkan apakah bijaksana untuk melakukan studi kasus tunggal atau mungkin bisa memperoleh pemahaman yang lebih baik tentang fenomena tersebut ketika melalui studi multiple case. Single case design merupakan desain penelitian studi kasus yang menekankan penelitian hanya pada sebuah unit kasus saja. Maka, desain kasus tunggal digunakan bila peneliti menemukan kasus tertentu yang unik (Munhall, 2001). Sehingga pertanyaan penelitian dari kasus penelitian perlu untuk menekankan kerangka konsep yang holistik dalam lingkungan sosialnya di mana penelitian berlangsung (Roberts \& Taylor, 2002). Peneliti biasanya terdorong untuk memahami fenomena secara menyeluruh, sehingga perlu memahami konteks dan melakukan analisis yang holistik. Laporan dalam penelitian kualitatif biasanya disertai dengan sintesis dan kesimpulan- kesimpulan dari peneliti.

Kemudian pada teknik pengumpulan data yang dilakukan adalah wawancara semistruktur, dengan pertanyaan open-ended terhadap topik yang akan diinvestigasi, yang dilakukan pada April 2020 (Langdridge, 2007); (Williams, R. W., G. W., Irvine, \& Hastings, 2010) menggunakan aplikasi video conference Google Meeting atau aplikasi video conference 
lainnya yang bersifat sinkronus dan telepon manual agar mendapatkan feedback secara real time, semua pembicaraan yang terjadi akan direkam sebagai hasil bukti yang ditranskip verbatim untuk nantinya dijadikan coding. Alasan peggunaan aplikasi video conference dan telepon dikarenakan saat ini peneliti tengah menghadapi pandemi global Covid-19 yang memaksakan untuk tetap wawancara dengan tidak bertemu secara langsung tetapi masih bersifat sinkronus. Ini dirancang agar informan dapat mengartikulasi sebanyak mungkin detail tentang pengalamannya (Langdridge, 2007). Informan dalam hal ini akan diberitahukan bahwa semua wawancara akan dijaga kerahasiaanya (diberikan consent form) dan tidak dibagikan untuk publik secara sembarangan. Wawancara dilakukan sesuai dengan kesediaan yang dipilih informan, wawancara akan berlangsung sekitar 45 hingga 90 menit dan di rekam dengan izin dari setiap informan (Booker, Cousin, \& Buck, 2019).

Analisis penelitian ini menggunakan model pattern matching (Yin, 2009), model pencocokan pola adalah salah satu teknik yang melibatkan perbandingan pola yang diprediksi dan atau efek dengan yang telah diamati secara empiris, dan identifikasi setiap varian atau kesenjangan (GAO, 1990). Catatan terperinci dari prediksi tersebut dan hasil yang relevan sangat penting. Tentu saja, semakin besar perbedaan dalam pola atau efek saingan, semakin mudah untuk melakukan pencocokan, dan semakin meyakinkan setiap temuan/ kesimpulan yang dihasilkan. Selain itu, konfirmasi prediksi berlawanan akan lebih meyakinkan daripada konfirmasi prediksi umum (Campbell, 2019).

Karena penelitian ini menggunakan konsep slow technology untuk memprediksi perkembangan agregator berita LINE Today di masa depan maka kriteria informan yang dibutuhkan dalam penelitian ini dibagi menjadi dua yakni kelompok informan khalayak dan kelompok informan jurnalis. Pendekatan slow tech diusulkan sebagai petunjuk atau kompas dalam mengarahkan orang menuju desain, produksi, dan penggunaan ICT yang baik, bersih, dan adil (Patrignani \& Whitehouse, 2015). Maka salah satu langkahnya ialah mengidentifikasi pemangku kepentingan ICT di antaranya adalah para stakeholder yang terlibat dalam pengembangan ICT agregator berita LINE Today yakni khalayak, jurnalis, dan developer. Namun, disebabkan kondisi saat penelitian dilakukan pada masa pandemi Covid-19 dan peneliti berlokasi di Jakarta yang merupakan episentrum dari pandemi tersebut di Indonesia, sehingga untuk mengatasi hal itu dengan menanyakan pendapat dan pandangan kelompok informan dari khalayak dan jurnalis terkait hal apa yang dapat disarankan dalam pengembangan agregator berita LINE Today dari sisi developer.

Pada kriteria kelompok informan khalayak di antaranya adalah: 1) Memiliki aplikasi LINE Today; 2) Merupakan pengguna aktif LINE Today secara harian; 3) Memiliki rentang usia antara 20-30 tahun (usia dengan penggunaan paling banyak di LINE Today (Parahita, 2019)); 4) Informan aktif dalam mencari informasi dan menggunakan fitur LINE Today. Sedangkan untuk kriteria kelompok informan jurnalis meliputi: (1) Bekerja secara terpisah di salah satu media daring yang tergabung dalam lima grup besar media Indonesia (Kelompok Kompas Gramedia (KKG), Global Mediacom (MNC), Visi Media Asia (Viva Group), CT Corp, Elang Mahkota Teknologi (EMTEK) (Arifin, 2013)); (2) Berita yang ditulis pernah dibagikan dalam LINE Today; (3) Pernah memiliki dan menggunakan LINE Today selama minimal satu tahun; (4) Aktif dalam menuliskan berita di media daring didasarkan aktivitas penulisan artikel dalam sehari.

Teknik yang digunakan untuk memeriksa keabsahan data mengenai penilaian individu nyatakan terhadap penggunaan LINE Today dengan menggunakan teknik Triangulasi Sumber yaitu memeriksa bukti dari sumber dan menggunakannya untuk membangun justifikasi yang koheren untuk satu tema penelitian, sesuai dengan penelitian kali ini yang menggunakan 
beberapa sumber data melalui berbagai perspektif informan. Peneliti dapat membandingkan kembali hasil pengamatan dengan data hasil wawancara yang telah direkam, memastikan tidak adanya pergeseran dalam mendefinisikan kode untuk makna selama proses coding, melakukan cross-check terhadap kode yang dikembangkan oleh peneliti yang berbeda dengan membandingkan hasil yang diperoleh secara independen (Creswell, 2014).

\section{HASIL DAN PEMBAHASAN}

Berdasarkan dari hasil pengumpulan data beserta coding dari indepth interview yang dilakukan bersama empat informan yakni UA, ALR, EN, dan AMS menunjukkan sejumlah temuan yang menarik baik dalam konteks jurnalisme digital di Indonesia dan pandangan mengenaipengembangan news aggregator berbasis human centered. Penelitian ini menggunakan 25 konsep untuk mengategorisasikan hasil jawaban para informan yang kemudian dirangkum ke dalam enam (6) dimensi temuan unik penelitian melalui proses axial coding. Hasil dari coding tersebut dijabarkan dalam tabel 1 yang kemudian akan diinterpretasikan sesuai dengan pertanyaan penelitian.

Tabel 1. Axial Coding Temuan Data

\begin{tabular}{|c|c|c|}
\hline Konsep & Subdimensi Temuan Data & Dimensi Temuan Data \\
\hline Penilaian Jurnalisme Digital Indonesia & \multirow{2}{*}{$\begin{array}{l}\text { Sosial-Budaya Jurnalisme } \\
\text { Digital Indonesia }\end{array}$} & \multirow{5}{*}{$\begin{array}{l}\text { Konteks Jurnalisme Digita } \\
\text { Indonesia }\end{array}$} \\
\hline Orientasi Khalayak pada Berita & & \\
\hline Orientasi pelaku media pada berita & \multirow{3}{*}{$\begin{array}{l}\text { Industri Jurnalisme Digital } \\
\text { Indonesia }\end{array}$} & \\
\hline Faktor Pendorong Jurnalisme Digital Indonesia & & \\
\hline Kepentingan Perusahaan Media Indonesia & & \\
\hline \multicolumn{2}{|l|}{ Pemanfaatan platform Berita } & \multirow{3}{*}{$\begin{array}{l}\text { Tindakan Mencari Infor- } \\
\text { masi \& Berita }\end{array}$} \\
\hline \multicolumn{2}{|l|}{ Keaktifan Mencari Berita } & \\
\hline \multicolumn{2}{|l|}{ Aktivitas Mencari Berita } & \\
\hline \multicolumn{2}{|l|}{ Alasan Menggunakan LINE Today } & \multirow{3}{*}{$\begin{array}{l}\text { Latar Belakang Peman- } \\
\text { faatan Agregator Berita }\end{array}$} \\
\hline \multicolumn{2}{|l|}{ Perbandingan dengan platform lain } & \\
\hline \multicolumn{2}{|l|}{ Preferensi tipe berita } & \\
\hline Penyajian Berita LINE Today & \multirow{3}{*}{ Budaya Teknologi LINE Today } & \multirow{5}{*}{$\begin{array}{l}\text { Pertimbangan Slow Tech- } \\
\text { nology }\end{array}$} \\
\hline Nilai Berita LINE Today & & \\
\hline Penulisan Berita LINE Today & & \\
\hline Kesan Positif LINE Today & \multirow{2}{*}{ Sikap Pengguna LINE Today } & \\
\hline Kesan Negatif LINE Today & & \\
\hline \multicolumn{2}{|l|}{ Peran Agregator Berita Pada Jurnalisme Digital } & \multirow{3}{*}{$\begin{array}{l}\text { Pengetahuan Umum News } \\
\text { Aggregator }\end{array}$} \\
\hline Temuan Isu di Agregator Berita & & \\
\hline \multicolumn{2}{|l|}{ Pemahaman Proses Agregator Berita } & \\
\hline Peran khalayak di LINE Today & \multirow{3}{*}{$\begin{array}{l}\text { Stakeholder ICT Agregator } \\
\text { Berita }\end{array}$} & \multirow{6}{*}{$\begin{array}{l}\text { Integrated Human Cen- } \\
\text { tered Design News Aggre- } \\
\text { gator }\end{array}$} \\
\hline Peran jurnalis di LINE Today & & \\
\hline Peran developer di LINE Today & & \\
\hline $\begin{array}{l}\text { Pesimisme Perkembangan ICT Agregator } \\
\text { Berita }\end{array}$ & \multirow{3}{*}{ Prediksi ICT Agregator Berita } & \\
\hline $\begin{array}{l}\text { Optimisme Perkembangan ICT Agregator } \\
\text { Berita }\end{array}$ & & \\
\hline Persepsi ICT Berbasis Human Centered & & \\
\hline
\end{tabular}

Sumber: Hasil pengolahan open coding peneliti

Potensi Pengembangan Agregator Berita Dengan Konsep Slow Technology Berbasis Human Centered (Ilham Fariq Maulana, Irwansyah) 
Intepretasi pada hasil coding menunjukkan sejumlah perbedaan pandangan dari kedua kelompok informan dalam pengembangan ICT agregator berita LINE Today. Namun, kedua kelompok ini memiliki kemiripan dan cenderung menyetujui hal yang sama dalam kondisi perkembangan jurnalisme digital saat ini. Salah satu temuan penelitian ditemui dalam konteks perkembangan jurnalisme digital Indonesia yang kini banyak didukung didorong oleh perkembangan teknologi serta mobilisasi individu yang cepat sehingga adopsi dari teknologi ini membawa perubahan di masyarakat tidak hanya dari sisi budaya dan sosial, akan tetapi juga dari sisi industri jurnalisme digital.

\section{Perkembangan Jurnalisme Digital Indonesia}

Selama ini perkembangan dari teknologi jurnalistik di Indonesia mengikuti dari konteks dan orientasi di media analog seperti cetak, televisi, dan radio. Namun, seiring dengan perkembangan ICT dalam berbagai bentuk dan fitur, salah satunya yang kini sudah digunakan masyarakat luas di era digital adalah smartphone. Berdasarkan dari hasil temuan data menunjukkan kedua kelompok menyetujui bahwa mobilisasi yang dihasilkan oleh teknologi smartphone mendorong perubahan dari era jurnalisme analog menjadi jurnalisme digital. Selain itu kelompok khalayak menunjukkan bahwa khalayak Indonesia yang kini cenderung untuk mencari informasi mengedepankan kecepatan dan konten berita yang ringan dan populer sehingga dapat dikatakan penggunaan jurnalisme digital di Indonesia lebih ke arah praktis. Seperti yang dijelaskan oleh informan EN yang menyadari bahwa jurnalistik digital makin diminati oleh khalayak dan semakin mudah didapatkan karena tersedianya pelbagai platform penyedia berita dan mobilisasi yang tinggi dari teknologi smartphone.

"Semakin banyak diminati, platform-nya semakin mudah. Ya pokoknya kayak lebih gampang aja gitu, di-reach sama orang-orang gitu. Maupun orang awam sekalipun yak. Gitu, bahkan bapak gua pun sekarang sudah enggak baca koran bacanya digital-digital. Kayaknya karena penggunaan smartphone deh." (EN, komunikasi personal).

Dari pernyataan tersebut juga memperlihatkan konteks perubahan sosial di masyarakat dalam menggunakan jurnalisme digital. Yakni ketika generasi yang lebih tua mulai beralih menggunakan platform digital sebagai sumber dalam pencarian berita dan tidak lagi menggunakan media analog seperti media cetak koran sebagai preferensi utamanya. Selain itu juga menekankan bahwa jurnalisme digital sekarang makin berkembang dan makin diminati oleh masyarakat. Maka temuan ini merujuk pada fungsi dari konsep slow tech yang pernah digunakan untuk menggambarkan dampak budaya dan sosial dari perangkat mobile ICT (Kopomaa, 2007). Pada pandangan berikutnya yang juga dijabarkan oleh UA, dari kelompok informan jurnalis menilai bahwa perkembangan dari jurnalisme digital Indonesia juga tidak lepas dengan adanya teknologi smartphone sehingga hal itu mendorong jurnalisme digital untuk terus berkembang.

"Jurnalisme digital itu menurut aku, dia udah masih berkembang karena masyarakat itu sekarang juga apa ya? Lebih memanfaatkan teknologi dari... dari handphone ketimbang televisi gitu dan dari sisi teknologi handphone sendiri kan kayak dia bisa mobile gitu ya dibawa ke mana-mana gitu. Itu dari sisi... jadi nggak kayak harus TV harus berdiam di suatu tempat untuk mendapatkan informasi gitu kan nggak jadi sekarang kita bisa mendapat informasi dimana kita berada. Itu dari sisi kali sisi apa kayak behavior-nya dulu, terus dari sisi kedua adalah sisi kecepatan sih ya? Kalau misalnya digital itu sekarang lebih cepat gitu kan update lebih cepat update ketimbang TV yang prosesnya lebih kompleks itu loh. Jadi informasi yang diterima masyarakat juga lebih cepat gitu. Itu dari sisi kecepatannya informasinya itu sendiri itu sih." (UA, komunikasi personal)

Lebih lanjut berdasarkan dari bentuk pernyataan yang diberikan diatas menunjukkan bagaimana tidak hanya faktor behavior atau perilaku khalayak yang juga memengaruhi 
dari perkembangan teknologi itu sendiri, melainkan juga bagaimana kecepatan sekarang menjadi orientasi yang penting bagi sikap masyarakat untuk menggunakan jurnalisme digital. Smartphone sendiri merupakan hasil pengembangan dari teknologi mobile yang dapat diartikan sebagai teknologi yang dipasangkan pada komunikasi seluler (Patil, Karhe, \& Aher, 2013) dimana teknologi ini berkembang dari model perangkat komunikasi dua arah seperti pada smartphone. Selain itu persoalan perkembangan teknologi mobile cukup erat korelasinya dengan perkembangan komputasi mobile yang didukung jaringan nirkabel (Patil et al., 2013). Sehingga bisa dikatakan bahwa internet membuka akses yang lebih besar akan jaringan pemanfaatan perangkat dekstop, teknologi mobile yang memungkinkan pengguna untuk dapat mengakses jaringan kapanpun dan dari manapun melalui perangkat gawai (Kumar, 2004).

Maka hal ini bisa menjelaskan perkembangan jurnalisme digital di Indonesia juga dipandang karena aktivitas untuk mengakses aplikasi platform penyedia berita seperti agregator berita. Hal tersebut ditunjukkan oleh data yang diperoleh oleh App Annie pengguna gawai pintar Indonesia setidaknya menghabiskan waktu hingga lebih dari 250 menit setiap harinya pada penggunaan aplikasi mobile (Maulana, 2018; Ramadhan, 2018). Fakta menarik lainnya adalah saat ini penterasi gawai pintar di Indonesia telah mencapai angka lebih dari 54 juta pengguna sejak tahun 2017 (Ramadhan, 2018). Lebih lanjut berdasarkan dari laporan App Annie 2017 pada Retrospectice: A Monumentral Year for the App Economy ini menjelaskan bahwa Indonesia merupakan negara dengan pengguna aplikasi dengan peringkat pertama di dunia (Ramadhan, 2018).

Namun, terdapat gagasan bahwa semakin mudahnya perkembangan teknologi dan kecepatan dalam memperoleh informasi, hal ini menyebabkan perubahan pula bagi arah bisnis dari media daring. Demi mengejar kecepatan, kuantitas, dan eksklusivitas agar menjadi leader issue banyak praktik dari jurnalisme digital kini mengarah pada kuantitas saja dan mengabaikan konteks isi sajian berita atau artikel pada khalayak. Hal ini dijelaskan oleh informan AMS yang melihat bagaimana orientasi bisnis media daring saat ini lebih berlomba untuk menjadi yang tercepat.

"Ngejar kuantitasnya aja cepet-cepetannya kayak gitu dan yang kayak gitu tuh udah dari dulu ketika memang.. akhirnya dia mulai berubah jadi digital tuh sampai sekarang yang dikejar itu kan di situ. Ya, ada sih beberapa media yang apa namanya yang udah mulai mau menaikan kualitasnya bikin tulisan-tulisan yang panjang, analisis mendalam tapi media-media digitalnya tetap masih banyak yang kayak gitu yang cuma ngejar kuantitas kualitas nya nggak terlalu." (AMS, komunikasi personal)

Melalui pandangannya juga menunjukkan bahwa masih ada media yang kembali memperbaiki isi kualitas tulisannya dengan memberikan konten artikel yang panjang dengan analisis yang mendalam. Namun, secara kontekstual masih banyak media yang lebih mengejar kuantitas dan mengabaikan kualitas kontennya. Sedikit berbeda dengan yang disampaikan oleh informan ALR, dari kelompok informan jurnalis yang melihat jika bahwa arah perkembangan industri jurnalistik digital Indonesia berubah disebabkan preferensi topik berita yang dibaca oleh khalayaknya sehingga hal itu memengaruhi bagaimana media harus mengakomodasikan berita yang diperbincangkan oleh masyarakat.

"Jadi kayak media digital itu lebih menuruti apa yang dimau pembaca jadi ketika ada judul bombastis ketika banyak judul clickbait itu sebenarnya ya karena memang pembaca Indonesia tuh taraf levelnya masih segitu. Mereka masih belum bisa diajak ke intelek banget buat mikir yang apa sih yang logi... yang bagus banget nggak bisa." (ALR, komunikasi personal)

Dari pernyataan yang dibuatnya menunjukkan konteks sosial-budaya di masyarakat 
dalam penggunaan ICT yang baru memang sudah berubah dan mengadopsi hal tersebut, tetapi itu merubah dari sisi kebiasaan khalayak untuk meningkatkan kualitas bacaan mereka. Meski Indonesia menjadi negara dengan pengguna aplikasi gawai teraktif, tetapi pada taraf minat baca masih cenderung belum banyak berubah. Sehingga dapat dikatakan konsep dari konteks jurnalisme digital di Indonesia cenderung mendeskripsikan bagaimana kondisi terbaru dari jurnalisme digital dari perspektif sosial-budaya yang terjadi karena budaya teknologi baru, dan industri jurnalistik digital yang juga mengadopsi mobilitas budaya teknologi tersebut.

\section{Penilaian Stakeholder LINE Today Pada Penyajian Berita Agregator}

Berangkat dari interpretasi data latar belakang dan tindakan para informan untuk menggunakan platform agregator berita LINE Today menunjukkan hasil yang cukup unik. Kelompok informan jurnalis cenderung sudah jarang menggunakan aplikasi LINE Today. Mereka menilai lebih banyak mendapatkan dan memperoleh informasi dari portal berita medianya langsung. Namun, kedua informan sama-sama menggunakan LINE Today karena berita mereka pernah diunggah ke dalam LINE Today. Selain itu keempat informan juga mencari preferensi berita lebih cenderung pada berita yang populer dan tengah diperbincangkan oleh masyarakat. Hal ini dijelaskan oleh informan AMS yang lebih mengutamakan berita yang panjang kemudian melanjutkannya pada berita pendek sebagai pelengkap atau supplementary.

"Walaupun buat gue pribadi itu kayak sebenarnya ada stratanya sendiri sih ini jadi artikel yang panjang tadi... itu yang diutamain untuk dibaca gitu istilahnya kayak gitu dan yang kedua... yang pendek-pendek tadi yang cuman kesannya informasi tambahan supplementary doang itu nah itu bagian yang kedua." (AMS, komunikasi personal).

Lebih lanjut lagi dalam pernyataannya juga akan menyoroti satu isu dahulu sebelum akhirnya tertarik dan bukan apa saja yang disajikan atau disediakan oleh agregator berita. Seperti yang dilakukan oleh informan EN yang menjelaskan dirinya akan tertarik dan menelusuri dari berbagai sumber platform berita apabila tertarik pada sebuah isu, sehingga tidak hanya berkutat pada agregator berita sendiri. Bagi informan jurnalis, seperti UA ketika memanfaatkan platform penyedia berita lebih cenderung ditujukan sebagai alat untuk mengecek atau tracking berita yang dinilai repetitif atau sudah banyak tersedia.

"Itu sebenarnya kalau repetitif itu jadi... jadi di online itu kan kita bisa ngecek ya. Jadi semacam kayak di-track gitu kan? Berita apa yang paling banyak dicari masyarakat, misal berita yang paling dicari masyarakat tuh sekarang soal pembukaan mal gitu. Nah nanti, ya udah kan kita kayak yang tadi aku bilang kan mengakomodasi apa aja yang dibutuhkan ...informasi yang dibutuhkan masyarakat." (UA, komunikasi personal)

Maka dari pernyataan lain dari informan UA melihat bahwa pencarian berita dan pemanfaatan platform berita tidak hanya ditujukkan untuk sekedar memperoleh informasi di tengah masyarakat, akan tetapi juga membantunya dalam pekerjaannya sebagai jurnalis dalam memetakan informasi-informasi yang tersedia di masyarakat. Maka hal tersebut merujuk pada kondisi mengalami proses informatization atau informatisasi yang disebabkan oleh teknologi informasi digital dimana ICT sudah masuk pada segala aspek publik dan kehidupan pribadi (Castells, 2011; Webster, 2006). Dapat dikatakan informatisasi memfasilitasi hadirnya infrastruktur informasi publik dan komunikasi yang baru dengan konektivitas dan interaktivitas sebagai kata kuncinya (van der Haak, Parks, \& Castells, 2012)). Tersedianya informasi yang luas inipun dimanfaatkan oleh para pelaku media agar dapat meningkatkan orientasi industri media digital yakni mengejar traffic pembaca. Dari interpretasi sebelumnya menunjukkan hubungan dari konsep latar belakang pemanfaatan agregator berita dengan tindakan mencari informasi 
100 | Kajian Jurnalisme

Volume 04 Nomor 01 Tahun 2020

DOI: $10.24198 / \mathrm{jkj} . \mathrm{v} 4 \mathrm{i} 1.27606$

dan berita, merujuk pada jukstaposisi antarkonsep yakni latar belakang pemanfaatan agregator juga hadir bersamaan dengan tindakan mencari informasi dan berita. Sehingga menunjukkan bentuk kesamaan dalam pemanfaatan, aktivitas, dan penggunaan agregator berita meski dengan tujuan yang berbeda

Maka merujuk dari data yang didapatkan dari keempat informan, penilaian pada penyajian berita dari agregator LINE Today terbagi atas tiga kriteria yakni penyajian, nilai, dan penulisan dari artikel atau berita itu sendiri. Pada masalah penyajian keempat informan menyetujui bahwa LINE Today selalu memilih berita yang tengah populer dan trending masyakarat sehingga hal itu mampu menarik khalayak untuk membaca melalui notifikasi muncul di pop-up. Seperti pengalaman yang dirasakan oleh informan EN yang menganggap bahwa LINE Today kerap memilih berita yang tengah populer. "Si LINE Today ini kayak udah milihin aja gitu. Ini lho berita yang lagi populer ini. Namun kalau dilihat desain di LINE today itu nggak banget soalnya kayak putih polos gitu doang 'kan?Nggak banget lebih lucuan di Detik.com." (EN, komunikasi personal)

Namun, dari pernyataannya juga didapatkan bahwa tampilan dari interface LINE Today tidaklah menarik baginya. Sehingga hal ini merujuk pada kesan negatif sebab informan juga membandingkannya dengan platform berita lain yang dinilainya lebih menarik dan lucu. Kesan positif dari penyajian berita justru datang dari kelompok informan jurnalis yang menjelaskan bahwa sajian berita dari LINE Today bisa meningkatkan jumlah pembaca dari berita yang ditulis lebih banyak. Sehingga hal tersebut membantu dalam meningkatkan traffic dari media daring itu sendiri. Kemudian pada kriteria nilai berita dari LINE Today, tiga informan menjelaskan bahwa kadang nilai berita yang mereka dapatkan setelah membaca berita yang disajikan oleh LINE Today cenderung kecil bahkan tidak ada sama sekali seperti terkesan receh, tidak jelas, dan biasa saja. Hal ini dijelaskan oleh informan ALR yang menjelaskan kecenderungan LINE Today hanya mengambil topik yang populer dan kadang konten beritanya bisa bagus atau sebaliknya. "Karena mereka ini kan? Nyaring dia nyaring kan dari beberapa site dan dia emang bener-bener ambil yang menarik jadi emang judulnya tuh bikin pengen kita klik. Jadi menarik aja. Cuman kadang ya isinya ya ada yang emang bagus ada yang enggak." (ALR, komunikasi personal)

Kemudian kriteria penilaian yang terakhir adalah penulisan berita di LINE Today, dari sini menunjukkan keempat informan juga sama-sama menilai bahwa bentuk penulisan berita di LINE Today cenderung seperti mengkopi ulang artikel asli, dan tidak benar-benar mengubah banyak tulisannya. Namun, masih mengikuti kaidah rewrite berita dengan menyertakan link artikel aslinya dan nama penulis dari artikel asli ke dalam berita yang diunggah kembali ke dalam LINE Today, seperti di dalam pernyataan informan UA.

"Kayaknya dia nggak banyak mengubah tulisan asli dan di bawahnya dia mencantumkan tulisan artikel asli ketika aku klik artikel asli dia ngelink ke link [nama portal berita]. Terus di sini juga ada nama aku, masih sesuai kaidah sih karena dia masih kayak ngasih link ke... itu aslinya .ke artikel aslinya gitu." (UA, komunikasi personal).

Agar lebih bisa mendapatkan gambaran dan interpretasi yang lebih kontekstual maka di sub bab ini akan ikut menginterpretasikan dari temuan data pada konsep pengetahuan umum news agregator. Salah satunya adalah temuan isu agregator berita, dari temuan data menunjukkan bahwa dari kelompok informan jurnalis cenderung tidak memperhatikan bentuk berita atau belum pernah menemukan berita yang repetitif, bias, dan irrelevan di LINE Today. Pada konsep isu agregator berita ini didasarkan dari temuan penelitian terdahulu yang menjelaskan masih adanya praktik repetisi berita, penyajian berita yang bias, dan isi berita yang tidak relevan (Choi \& Kim, 2017; Haim et al., 2018). Namun, pada temuan data yang yang bersumber dari 
kelompok informan khalayak, keduanya pernah beberapa kali menemukan tipe-tipe berita tersebut. Seperti yang dijelaskan oleh informan AMS yang menilai adanya berita repetitif dengan judul yang berbeda tetapi sumber yang dikutip tetap sama, dan isinya pun mirip.

"Kadang-kadang udah pernah tuh waktu itu isu tentang apa ya? Kalau enggak salah isu tentang vaksin itu ada habis berita yang itu ditampilkan. Habis itu nanti ditampilkan lagi gitu tapi dengan judul yang berbeda, tapi sebenarnya isinya mirip kutipan-kutipannya, sumbernya juga, repetitif jadinya..." (AMS, komunikasi personal).

Perbedaan dari temuan isu dari kedua kelompok ini cukup unik, karena para informan jurnalis yang merupakan pelaku media sehingga cenderung dengan mudah bisa menangkap apabila ada tipe-tipe berita seperti yang dijelaskan. Namun, apabila dilihat lagi informan jurnalis mungkin tidak menemukan isu tersebut sebab keduanya sudah jarang menggunakan agregator berita sebagai sumber utamanya dalam mencari berita, akan tetapi lebih pada portal beritanya langsung karena disesuaikan dengan kebutuhan pekerjaan. Sehingga informan sulit untuk recall pengalaman tersebut apabila pernah atau tidak pernah menemui tipe-tipe berita terkait. Sedangkan kelompok informan khalayak lebih mudah recall pengalaman dalam menemukan tipe-tipe berita karena menggunakan LINE Today sebagai agregator berita utama mereka dan frekuensi penggunaan mereka secara harian.

\section{Potensi Perkembangan LINE Today Melalui Integrasi Peran Stakeholder ICT}

Berdasarkan dari pemaparan dan interpretasi data pada sub bab sebelumnya, bisa didapatkan konteks kritik dari sajian berita LINE Today. Maka sub bab ini akan menjelaskan pada konsep-konsep yang dapat mendukung slow technology yang berbasis human centered design sehingga tujuan akhirnya dapat menghapus bias dan menekankan nilai dan etika (Deloitte, 2020). Maka penelitian ini memberikan gagasan untuk sebuah integrasi peran dari stakeholder dari LINE Today untuk bisa saling berkolaborasi dan terlibat ikut berpikir ke depan dalam jangka panjang teknologi (Patrignani \& Whitehouse, 2015).

Sebelumnya akan dijabarkan dulu bagaimana pemahaman dari stakeholder mengenai peran agregator berita terhadap jurnalisme digital ada perbedaan pandangan dari hal ini yang menunjukkan informan khalayak cenderung menganggap peran agregator berita seperti LINE Today menjadi distributor dan pengepul berita dengan membagikan berita yang populer agar ramai dibaca oleh khalayak sehingga bisa membantu traffic dari media daring itu sendiri. Seperti pernyataan yang diberikan oleh informan EN yang menganggap LINE Today layaknya pengepul berita

"Dia di bagian tukang distribusi kali ya, kayak pengepul kalau kata gua, kalau misalnya di dagangan itu kayak pengepul terus dia bagiin ke orang lain atau kayak dia apa ya kayak semacam, "Eh lu kalau mau jualan terus ramai kirim ke gua." Kayak gitu perannya apa tuh maksudnya...kayak penyedia ruang untuk maksudnya, "Kalau mau ramai ya ke gue aja dulu."

Sedangkan pada pandangan lainnya peran dari agregator berita itu sendiri tidak banyak berpengaruh atau memberi keuntungan baginya sebagai jurnalis, menurut informan UA, dirinya kadang tidak aware peran dari news aggregator seperti LINE Today. Namun, dirinya menyadari bahwa ada perbedaan kriteria dan budaya perusahaan dalam raihan atau capaian kerja seperti key performance indicator (KPI). Sehingga ia menganggap peran dari agregator berita tidak bisa dipukul rata ke semua media daring yang ada di Indonesia.

Merujuk pada hal tersebut maka berdasarkan hasil data yang diperoleh dari keempat informan, mereka menjelaskan apa saja peran yang harus dan perlu dilakukan dari masingmasing stakeholder yakni khalayak, jurnalis, dan developer untuk mengembangkan kualitas 
102 | Kajian Jurnalisme

Volume 04 Nomor 01 Tahun 2020

DOI: $10.24198 / \mathrm{jkj} . \mathrm{v} 4 \mathrm{i} 1.27606$

dan kinerja dari agregator berita LINE Today. Maka berdasarkan peran dari khalayak keempat informan menjelaskan peran dari khalayak menjadi penting seperti masyarakat harus dan mau memilih serta membaca berita yang bagus sehingga memiliki power terhadap LINE Today, yakni pada preferensi berita yang akan diangkat atau dibagikan kepada penggunanya. Selain itu adalah aktif menggunakan fitur komentar dan membuat forum untuk menyampaikan kritik dan saran kriteria konten berita yang lebih baik. Sehingga apa yang dipikirkan, dirasakan, dan dialami oleh khalayak dapat menjadi bahan pertimbangan bagi developer LINE Today nantinya. Oleh informan EN, memberikan keterengan tersebut. "Itu harus pinter milih. Kalau misalnya tadi masuk apa sih kelihatan kita milih berita yang mana aja nih yang interest buat kita. Kayak ya udah gunain hak lu buat itu gitu, untuk jadiin content aggregator kita itu bagus gitu nggak nggak asal aja gitu." (EN, komunikasi personal)

Melanjutkan pada peran jurnalis memiliki sejumlah pemikiran dan gagasan yang perlu untuk digunakan dan dikembangkan oleh para pelaku media khususnya, tidak hanya jurnalis, melainkan juga editor dan pemimpin redaksinya. Peran-peran yang dapat diambil oleh para jurnalis dalam pengembangan LINE Today seperti perlu untuk menentukan arah berita dan tulisan artikel, artinya jurnalis sendiri perlu memiliki tujuan dan analisis jurnalis perlu memenuhi kriteria standar dari etika jurnalistik serta nilai berita. Hal ini seperti yang dijabarkan oleh informan UA yang menilai ada kemampuan dari jurnalis yang harusnya ditampilkan. "Ya menentukan arah pemberitaan. Kalau misalnya sekedar nulis kan mungkin AI bisa ya? Tapi kan berita itu kayak butuh... butuh... butuh tujuan gitu lho, butuh tujuan, butuh makna gitu apa yang ingin disampaikan gitu kan." (UA, komunikasi personal)

Karena salah satu kriteria dan aspek pertama dari aturan pemilihan berita adalah nilai berita (news values) (Wendelin et al., 2017). Maka agregator berita akan mendasarkan kurasi dan penyajian berita dari nilai berita. Peran penting lainnya dari jurnalis adalah perlu memiliki ruh analisa dan keingintahuan sehingga hal itu bisa berdampak pada gaya penulisan dan kualitasnya. Namun, karena masih terikat dengan tempatnya bekerja, sehingga kualitas tulisan jurnalis juga bentuk tanggung jawab editor dan pemimpin redaksi media tidak hanya satu pelaku media saja.

Kemudian peran stakeholder yang ketiga adalah berupa saran dan masukan bagi developer dari LINE Today itu sendiri. Sehingga mereka mampu mendesain teknologi yang berbasis human centered. Pertama, developer perlu untuk mengambil berita dari media-media yang verified agar bisa dipertanggungjawabkan, sebabnya media-media ini sudah mengemas beritanya sebaik mungkin sehingga apabila terjadi isu dapat dikritik dan direvisi kembali. Selain itu, pihak developer perlu mempertimbangkan dalam membuat bentuk artikel yang bertipe teaser sehingga menarik keaktifan khalayak dalam membaca dan klik di artikel aslinya. Ketiga, memiliki sumber daya manusia (SDM) yang berlatar belakang jurnalistik dan mengetahui kode etik jurnalistik. Sehingga peran ini membutuhkan keputusan yang tepat dari otoritas LINE Today terutama dalam masalah untuk memiliki kriteria kuratorial dari berita yang hendak diunggah dengan memperketat kebijakan dan requirement dari berita yang disajikan. Kemudian pada sisi aplikasi developer perlu untuk mengembangkan fitur user experience terutama dalam masalah feedback penggunanya seperti membuat forum komunitas sendiri. Hal ini disampaikan oleh informan AMS yang memberikan contoh pada pengembangan tersebut.

"Karena kalau buat kualitas itu yang kayak gitu tuh perlu banget gitu loh jadi dia tahu apa yang kita... Kita ingin maksudnya apa yang yang masuk kriteria news buat para usernya ini. Itu untuk menjadi masukan mereka karena kan kalau melihat ada satu online store itu bukan online store marketplace yang besar itu. Mereka menyediakan kanal komunitas yang isinya itu adalah masukan buat marketplace itu yang itu isinya ada penjual pembeli segala macam itu tuh bagus yang kayak gitu. Jadi, jadi kayak satu forum sendiri untuk menyuarakan apa yang mereka inginkan untuk menjadi institusi itu 
lebih baik. LINE Today itu kalau emang ingin menjadi lebih baik menyediakan kontenkonten yang berkualitas dan itu kan juga jadi riset development-nya juga gitu loh dia bikin satu entah forum, entah bentuk komunitas, kritik dan saran yang paling simpel kayak gitu."

Lebih lanjut, agar bisa menjadi ukuran dan batasan dari potensi integrasi peran antar stakeholder ini maka bisa dilihat potensi kemungkinannya apakah dapat dilakukan atau akan mengalami hambatan. Dari sisi hambatan, informan ALR menganggap jurnalis meski sudah membuat berita bagus akan tetapi bisa kalah apabila khalayak dan pasarnya masih seperti sekarang ini.

"Jadi gini ketika jurnalisnya bikin berita bagus pun kalau nggak laku ya sulit. Soalnya itu adanya di pasarnya sih, karena jurnalis yang bikin berita bagus pun akan tetap kalah sama pasar dan terseret ombak dan agregator pasti ambil dari dia 'kan? Ketika jurnalisnya udah keseret ombak ya udah, agregatornya keseret ya udah pasarnya gitugitu aja kayak Indonesia sekarang digital online-nya tarafnya ya segini-segini doang." (ALR, komunikasi personal).

Sehingga hal ini perlu diatasi dari kesadaran baik khalayak dan jurnalis sebab bisa dikatakan nilai berita merupakan kriteria yang relevan baik bagi jurnalis dan audiensnya (Eilders; Lee; Shoemaker \& Reese dalam Wendelin et al., 2017). Optimisme mengenai hal ini muncul dari informan mempersepsikan ICT yang berbasis human centered secara terintegrasi sangat diperlukan dan tidak bisa dipisahkan. Apalagi manusia perlu berperan aktif dalam membaca dan menelusuri sumber asli artikel. Konsep ini sesuai dengan pemahaman Good ICT yang merujuk pada ICT yang dikembangkan dengan menempatkan manusia sebagai pusat perhatian teknologi itu sendiri (Patrignani \& Whitehouse, 2015). Sehingga konsep ini memperkenalkan kesadaran eksplisit keseimbangan antara meningkatnya kecepatan ICT dan kecepatan pemrosesan informasi manusia yang lebih terbatas. Hal ini dijelaskan oleh informan EN yang memberi optimisme terhadap potensi desain ICT ini.

"Sehingga kalau misalnya ada berita repetisi atau berita-berita bias tadi terus berita yang nggak nyambung tuh langsung di-cut sendiri gitu bahwa, "Gak boleh lho ada yang kayak gini." Gitu. Lihat dong komentar-komentarnya, jadi apa ya SDM-nya di dalam si developer-nya Line Today-nya aja gitu yang harus dibenerin." (EN, komunikasi personal)

\section{SIMPULAN}

Penelitian ini memberikan gagasan dan ide baru dalam pengembangan news aggregator LINE Today di konteks Indonesia. Selain itu mencoba untuk mengisi gap dari penelitian terdahulu (Choi \& Kim, 2017; Haim et al., 2018) mengenai isu dan masalah yang kerap ditemui dari news aggregator sehingga mampu memberikan solusi konstruktif melalui potensi pengembangan dengan konsep slow technology yang berbasis human centered. Karena ICT haruslah mencerminkan nilai-nilai manusia, seperti kepercayaan, integritas, dan kejujuran semua faktor emosional yang dirasakan manusia (Deloitte, 2020). Juga cepatnya perkembangan dari jurnalisme digital di Indonesia yang perlu dibarengi dengan kemampuan ICT yang mengikuti kebutuhan manusia itu sendiri.

Keterbatasan dari penelitian ini adalah belum melakukan perolehan data dari pihak developer LINE Today disebabkan kondisi pandemi Covid-19 saat ini yang tengah terjadi sehingga belum melengkapi pandangan stakeholder secara detail. Selain itu wawancara tatap muka menggunakan video conference yang menuai berbagai hambatan dan sangat dimungkinkan informan yang diwawancarai memiliki sikap yang berbeda antara dirinya saat wawancara secara langsung dan saat wawancara di video conference. 
104 | Kajian Jurnalisme

Volume 04 Nomor 01 Tahun 2020

DOI: $10.24198 / \mathrm{jkj} . \mathrm{v} 4 \mathrm{i} 1.27606$

\section{DAFTAR PUSTAKA}

Arifin, P. (2013). Persaingan Tujuh Portal Berita Online Indonesia berdasarkan Analisis Uses and Gratifications. Jurnal ILMU KOMUNIKASI, 10(2), 195-211. https://doi.org/10.24002/ jik.v10i2.353

Booker, S. Q., Cousin, L., \& Buck, H. G. (2019). "Puttin' on”: Expectations Versus Family Responses, the Lived Experience of Older African Americans With Chronic Pain. Journal of Family Nursing, 25(4), 533-556. https://doi.org/10.1177/1074840719884560

Borbasi, S. (2004). Navigating the Maze of Nursing Research: An Interactive Learning Adventure. Elsevier Australia.

Cahyo, D. (2017). LINE Today, Media Yang Merebut Hati Masyarakat.

Campbell, J. L. (2019). Online Self-Identities, Social Norms, and the Performance of Self in Real-Life. International Journal of Virtual Communities and Social Networking, 10(2), 24-40. https://doi.org/10.4018/ijvcsn.2018040102

Castells, M. (2011). The Rise of the Network Society, The Information Age. In Economy, Society and Culture (Vol. 1, pp. xvii-xliv).

Choi, S., \& Kim, J. (2017). Online news flow: Temporal/spatial exploitation and credibility. Journalism: Theory, Practice \& Criticism, 18(9), 1184-1205. https://doi. org/10.1177/1464884916648096

Chyi, H. I., Lewis, S. C., \& Zheng, N. (2016). Parasite or Partner? Coverage of Google News in an Era of News Aggregation. Journalism \& Mass Communication Quarterly, 93(4), 789-815. https://doi.org/10.1177/1077699016629370

Creswell, J. W. (2014). Research design: Qualitative, quantitative, and mixed methods approaches. 4th Edition. In SAGE Publication. https://doi.org/10.1007/s13398-0140173-7.2

Deloitte. (2020). Tech Trends 2020. Deloitte Insights, 1-130.

Dewan Pers. (2018). Media Siber Dominasi Pengaduan.

Haim, M., Graefe, A., \& Brosius, H. (2018). Burst of the Filter Bubble? Digital Journalism, 6(3), 330-343. https://doi.org/10.1080/21670811.2017.1338145

Hallnäs, L., \& Redström, J. (2001). Slow technology - Designing for reflection. Personal and Ubiquitous Computing, 5(3), 201-212. https://doi.org/10.1007/PL00000019

Hermans, L., \& Drok, N. (2018). Placing Constructive Journalism in Context. Journalism Practice, 12(6), 679-694. https://doi.org/10.1080/17512786.2018.1470900

Hidayat, D., \& Anisti, A. (2015). Wartawan Media Now dalam Mengemas Berita: Perspektif Situational Theory. Jurnal ASPIKOM, 2(5), 295. https://doi.org/10.24329/aspikom. v2i5.81

Kopomaa, T. (2007). Affected by the mobiles: mobile phone culture, text messaging, and digital welfare services, in Pertierra, $R(E d s)$. The Social Construction and Usage of Communication Technologies: Asian and European Experience, 48-59.

Kumar, S. (2004). Mobile communications: Global trends in the 21 st century. International Journal of Mobile Communications, Vol. 2, pp. 67-86. https://oi.org/10.1504/ IJMC.2004.004488

Langdridge, D. (2007). Phenomenological psychology. Encyclopedia of Psychology, 6.

Maulana, R. (2018). App Annie: Durasi Penggunaan Aplikasi Mobile Indonesia Tertinggi di Dunia.

Munhall, P. (2001). Nursing research: A qualitative perspective. (3rd ed.). Canada: Jones and Bartlett Publisher.

Parahita, T. A. (2019). Analisis Isi Tingkat Keberimbangan Berita Rubrik News Dan Showbiz

Potensi Pengembangan Agregator Berita Dengan Konsep Slow Technology Berbasis Human Centered (Ilham Fariq Maulana, Irwansyah) 
Yang Disajikan Dalam Portal Berita Line Today. Interaksi Online, 26(2), 21-42.

Patil, C. S., Karhe, R. R., \& Aher, M. A. (2013). Development of Mobile Technology: A Survey. International Journal of Advanced Research in Electrical, Electronics and Instrumentation Engineering, 1(5), 374-379.

Patrignani, N., \& Whitehouse, D. (2015). Slow Tech: a roadmap for a good, clean and fair ICT. Journal of Information, Communication and Ethics in Society, 13(3/4), 268-282. https:// doi.org/10.1108/JICES-05-2015-0014

Prihastomo, W. (2019). Lebih Mudah dan Praktis, Aplikasi Agregator Berita Makin Laris.

Ramadhan, B. (2018). Indonesia Tempati Peringkat Pertama Negara Teraktif Menggunakan Aplikasi Mobile.

Roberts, K. L., \& Taylor, B. J. (2002). Nursing research process: An Australian perspective. Australia: Nelson Australia Pty.

van der Haak, B., Parks, M., \& Castells, M. (2012). The Future of Journalism: Networked Journalism. International Journal of Communication 6, 2923-2938.

Wendelin, M., Engelmann, I., \& Neubarth, J. (2017). User Rankings and Journalistic News Selection. Journalism Studies, 18(2), 135-153. https://doi.org/10.1080/146167 0X.2015.1040892

Widodo, Y. (2017). Menyoal Etika Jurnalisme Kontemporer: Belajar dari OhmyNews. Jurnal ASPIKOM, 1(1), 41. https://doi.org/10.24329/aspikom.vli1.7

Williams, R. W., R., G. W., Irvine, F. E., \& Hastings, R. P. (2010). Exploring decision making in intellectual disability nursing practice: A qualitative study. Journal of Intellectual Disabilities, 14(3), 197-220. Retrieved from https://doi.org/10.1177/1744629510386289

Yin, R. K. (2009). Case study research: Design and methods (3rd ed.). Thousand Oaks, CA: Sage Publications, Inc. 